\title{
Local control and toxicity outcomes of stereotactic radiosurgery for spinal metastases of gastrointestinal origin
}

\author{
Navjot Sandhu, BS, ${ }^{1}$ Kathryn R. K. Benson, BA, ${ }^{1}$ Kiran A. Kumar, MD, MBA, ${ }^{1,3}$ Rie V. Eyben, MS, ${ }^{1}$ \\ Daniel T. Chang, MD, Iris C. Gibbs, MD, ${ }^{1}$ Steven L. Hancock, MD, ${ }^{1}$ Antonio Meola, MD, ${ }^{2}$ \\ Steven D. Chang, MD, ${ }^{2}$ Gordon Li, MD, ${ }^{2}$ Melanie Hayden-Gephart, MD, ${ }^{2}$ Scott G. Soltys, MD, ${ }^{1}$ and \\ Erqi L. Pollom, MD, MS 1
}

Departments of ${ }^{1}$ Radiation Oncology and ${ }^{2}$ Neurosurgery, Stanford University School of Medicine, Stanford, California; and ${ }^{3}$ UT Southwestern Medical Center, Dallas, Texas

OBJECTIVE Colorectal cancer (CRC) and other gastrointestinal (GI) cancers are believed to have greater radioresistance than other histologies. The authors report local control and toxicity outcomes of stereotactic radiosurgery (SRS) to spinal metastases from $\mathrm{GI}$ primary cancers.

METHODS A retrospective single-center review was conducted of patients with spinal metastases from GI primary cancers treated with SRS from 2004 to 2017. Patient demographics and lesion characteristics were summarized using medians, interquartile ranges (IQRs), and proportions. Local failure (LF) was estimated using the cumulative incidence function adjusted for the competing risk of death and compared using Gray's test for equality. Multivariable analyses were conducted using Cox proportional hazard models, adjusting for death as a competing risk, on a per-lesion basis. Patients were stratified in the Cox model to account for repeated measures for clustered outcomes. Median survival was calculated using the Kaplan-Meier method.

RESULTS A total of 74 patients with 114 spine lesions were included in our analysis. The median age of the cohort was 62 years (IQR 53-70 years). Histologies included CRC (46\%), hepatocellular carcinoma (19\%), neuroendocrine carcinoma (13\%), pancreatic carcinoma (12\%), and other (10\%). The 1- and 2-year cumulative incidence rates of LF were $24 \%(95 \%$ confidence interval $[\mathrm{Cl}] 16 \%-33 \%)$ and $32 \%(95 \% \mathrm{Cl} 23 \%-42 \%)$, respectively. Univariable analysis revealed that older age $(p=0.015)$, right-sided primary CRCs $(p=0.038)$, and single fraction equivalent dose (SFED; $\alpha / \beta=10)$ $<20$ Gy $(p=0.004)$ were associated with higher rates of LF. The 1-year cumulative incidence rates of LF for SFED $<20$ $\mathrm{Gy}_{10}$ versus SFED $\geq 20 \mathrm{~Gy}_{10}$ were $35 \%$ and $7 \%$, respectively. After controlling for gross tumor volume and prior radiation therapy to the lesion, SFED $<20 \mathrm{~Gy}_{10}$ remained independently associated with worse LF (hazard ratio $2.92,95 \% \mathrm{Cl}$ $1.24-6.89, p=0.014)$. Toxicities were minimal, with pain flare observed in 6 patients ( $8 \%$ ) and 15 vertebral compression fractures (13\%).

CONCLUSIONS Spinal metastases from GI primary cancers have high rates of LF with SRS at a lower dose. This study found that SRS dose is a significant predictor of failure and that prescribed SFED $\geq 20 \mathrm{~Gy}_{10}$ (biological equivalent dose $\geq$ $60 \mathrm{~Gy}_{10}$ ) is associated with superior local control.

https://thejns.org/doi/abs/10.3171/2020.1.SPINE191260

KEYWORDS colorectal cancer; spine metastasis; stereotactic radiosurgery; gastrointestinal cancers; radioresistance; local control; oncology

ABBREVIATIONS BED = biological equivalent dose; $\mathrm{Cl}=$ confidence interval; $\mathrm{CRC}=$ colorectal cancer; $\mathrm{EBRT}=$ external beam radiation therapy; $\mathrm{ECOG}=$ Eastern Cooperative Oncology Group; GI = gastrointestinal; GTV = gross tumor volume; GTV Dmin = minimum dose to GTV; HR = hazard ratio; IQR = interquartile range; LF = local failure; PTV = planning tumor volume; RTOG = Radiation Therapy Oncology Group; SBRT = stereotactic body radiotherapy; SFED = single fraction equivalent dose; SINS = Spine Instability Neoplastic Score; SRS = stereotactic radiosurgery; VCF = vertebral compression fracture.

SUBMITTED October 30, 2019. ACCEPTED January 7, 2020.

INCLUDE WHEN CITING Published online March 6, 2020; DOI: 10.3171/2020.1.SPINE191260. 
$\mathrm{A}$ $\mathrm{N}$ estimated $30 \%-50 \%$ of cancer patients experience metastatic spread to their vertebral column that can often result in severe pain, instability, and neurological compromise. ${ }^{44}$ Radiation therapy is an established treatment modality for these patients; however, local control and complete pain relief rates are low and not durable with the palliative doses that have historically been used, particularly in the setting of extended survivals with improvements in systemic therapy. ${ }^{19,41}$ In the past decade, stereotactic body radiotherapy (SBRT), or stereotactic radiosurgery (SRS), has allowed the conformal and safe delivery of high radiation doses to small targets and has been increasingly used to treat tumors in extracranial sites. ${ }^{3,46}$ Both prospective and retrospective data have shown local control exceeding $80 \%$ associated with SBRT/SRS for the treatment of spinal tumors, ${ }^{13,18}$ even those of radioresistant histologies. ${ }^{14,15,42,46}$

There has been concern that metastases from gastrointestinal (GI) cancers are particularly radioresistant and have poorer local control despite high-dose irradiation..$^{5,32}$ In this study, we assessed the outcomes of patients who underwent SRS for GI spinal metastases at our institution and hypothesized that spinal metastases from a GI origin have high rates of local failure (LF). We also determined factors associated with LF.

\section{Methods \\ Cohort}

With the approval of the Stanford University IRB, we performed a retrospective cohort study of patients with spinal metastases from GI primary cancers treated with SRS from April 2004 to December 2017. Patients were required to have at least one imaging follow-up, which included CT, PET, and/or MRI.

\section{Baseline Characteristics and Outcomes}

Patient, tumor, and treatment characteristics were collected. We determined the number of chemotherapy regimens previously received as well as any prior surgery and radiation therapy to the target spinal metastases. SRS treatment characteristics collected included gross tumor volume (GTV), planning tumor volume (PTV), dose, number of fractions, single fraction equivalent dose (SFED), biological equivalent dose (BED), and minimum dose to the GTV (GTV Dmin). The SFED and BED were calculated via the linear-quadratic model, with $\alpha / \beta=10$. The Spine Instability Neoplastic Score (SINS), which assesses the tumor-related instability of the spinal column, was calculated for each lesion prior to SRS. Sidedness of primary colorectal cancer (CRC) was recorded, with splenic flexure, descending, rectum, sigmoid, and distal one-third of transverse colon cancers considered left-sided, and cecum, ascending, hepatic, and proximal two-thirds of the transverse colon cancers considered right-sided.,26

Patients were treated using the CyberKnife radiosurgery system (Accuray). Patients were immobilized using an Aquaplast face mask (WFR/Aquaplast) for cervical spine lesions or custom-made vacuum bag mold (Smithers Medical Products, Inc.) for thoracic or lumbar spine lesions. Contrast-enhanced 1.25-mm-thick CT scans and contiguous axial 2.0-mm-thick stereotactic MR images were obtained through the spinal region of interest with the patient supine. The CT and MR image sets were then fused on the treatment-planning workstation, and target volumes were delineated on the treatment-planning CT per consensus guidelines. ${ }^{10}$ Prescription dose and fractionation were chosen according to physician best judgment based on tumor location, size, and prior treatment characteristics, and ranged in our cohort from $\mathrm{SFED}_{10} 14$ Gy to $\mathrm{SFED}_{10} 24 \mathrm{~Gy}$. The maximum dose constraints used for spinal cord and cauda equina were $\mathrm{SFED}_{10} 14 \mathrm{~Gy}$ and $16 \mathrm{~Gy}$, respectively. No specific dose constraint was used for spinal nerves.

Patients were typically followed with imaging and evaluated by both the treating neurosurgeon and radiation oncologist every 3 months after SRS. LF was defined by an increase in size of the treated lesion on serial followup imaging after completion of SRS. Radiation toxicity included vertebral compression fracture (VCF) and pain flare (increase in pain within 6 days of treatment). ${ }^{2}$

\section{Statistical Analysis}

Patient demographics and lesion characteristics were summarized using medians, interquartile ranges (IQRs), and proportions. The follow-up duration was calculated from last date of treatment to last date of clinical followup. Because patients could have multiple spinal metastases treated with SRS, analyses were conducted at the lesion level. Lesions treated with repeat SRS for local recurrences were captured only once at the time of initial SRS. LF was estimated using the cumulative incidence function adjusted for the competing risk of death and compared using Gray's test for equality. Multivariable analyses were conducted using Cox proportional hazard models adjusting for death as a competing risk on a per-lesion basis. Patients were stratified in the Cox model to address the repeated measures for clustered outcomes. Median survival was calculated using the Kaplan-Meier method. All endpoints were calculated from the date of SRS treatment. A p value $<0.05$ was regarded as statistically significant. Statistical analyses were conducted using SAS (version 9.4, SAS Institute Inc.) and graphic representation of findings was generated using GraphPad Prism (version 7, GraphPad Software).

\section{Results}

\section{Patient and Lesion Characteristics}

A total of 74 patients who received SRS to 114 spinal metastases were included. The median age of the cohort was 62 years (IQR 53-70). Tumor histologies included CRC ( $\mathrm{n}=34,46 \%)$, hepatocellular $(\mathrm{n}=14,19 \%)$, neuroendocrine $(\mathrm{n}=10,13 \%)$, pancreatic $(\mathrm{n}=9,12 \%)$, and other $(\mathrm{n}=7,10 \%)$ GI cancers. Patient-level characteristics are summarized in Table 1.

The most common spinal metastasis location was thoracic $(n=57,50 \%)$, followed by lumbar $(n=40)$, cervical $(n=12)$, and sacral $(n=5$; Table 2$)$. Sixteen lesions $(14 \%)$ were treated with surgical procedures prior to SRS, including 4 vertebroplasties, 2 corpectomies, and 10 laminectomies. Spinal instrumentation was used to restore spinal stability, to prevent vertebral body collapse (or restore ver- 
TABLE 1. Patient-level characteristics

\begin{tabular}{|c|c|c|c|}
\hline Parameter & $\begin{array}{l}\text { Whole } \\
\text { Cohort }\end{array}$ & $\begin{array}{c}\text { SFED }<20 \\
\mathrm{~Gy}_{10}\end{array}$ & $\begin{array}{c}\text { SFED } \geq 20 \\
\mathrm{~Gy}_{10}\end{array}$ \\
\hline No. of pts & 74 & 40 & 34 \\
\hline Median age (IQR), yrs & $62(53-70)$ & $64(53-71)$ & $59(52-67)$ \\
\hline \multicolumn{4}{|l|}{ Sex, n (\%) } \\
\hline Male & $44(59)$ & $28(64)$ & $16(36)$ \\
\hline Female & $30(41)$ & $12(40)$ & $18(60)$ \\
\hline \multicolumn{4}{|l|}{ Race/ethnicity, n (\%) } \\
\hline White & $34(46)$ & $18(53)$ & $16(47)$ \\
\hline Nonwhite & $40(54)$ & $22(55)$ & $18(45)$ \\
\hline \multicolumn{4}{|l|}{ Performance status, $n(\%)$} \\
\hline ECOG score 0-1 & $50(68)$ & $26(52)$ & $24(48)$ \\
\hline ECOG score 2-4 & $23(31)$ & $14(61)$ & $9(39)$ \\
\hline Unknown & $1(1)$ & - & $1(100)$ \\
\hline \multicolumn{4}{|l|}{ Histology, n (\%) } \\
\hline CRC & $34(46)$ & $20(59)$ & $14(41)$ \\
\hline Lt-sided & $20(59)$ & $11(55)$ & $9(45)$ \\
\hline Rt-sided & $14(41)$ & $9(64)$ & $5(36)$ \\
\hline $\mathrm{HCC}$ & $14(19)$ & $9(64)$ & $5(36)$ \\
\hline Neuroendocrine & $10(13)$ & $3(30)$ & $7(70)$ \\
\hline Pancreas & $9(12)$ & $4(44)$ & $5(56)$ \\
\hline Other & $7(10)$ & $4(57)$ & $3(43)$ \\
\hline \multicolumn{4}{|l|}{ Grade, n (\%) } \\
\hline Poorly differentiated & $7(9)$ & $2(29)$ & $5(71)$ \\
\hline Moderately differentiated & $28(38)$ & $17(61)$ & $11(39)$ \\
\hline Well-differentiated & $13(18)$ & $6(46)$ & $7(54)$ \\
\hline Unknown & $26(35)$ & $15(58)$ & $11(42)$ \\
\hline \multicolumn{4}{|l|}{ KRAS mutation, $\mathrm{n}(\%)$} \\
\hline KRAS-wt & $25(34)$ & $11(44)$ & $14(56)$ \\
\hline KRAS-mut & $7(9)$ & $4(57)$ & $3(43)$ \\
\hline Unknown/NA & $42(57)$ & $25(60)$ & $17(40)$ \\
\hline \multicolumn{4}{|l|}{ BRAF mutation, $\mathrm{n}(\%)$} \\
\hline$B R A F$-wt & $16(22)$ & $9(56)$ & $7(44)$ \\
\hline$B R A F-$ mut & $1(1)$ & $1(100)$ & - \\
\hline Unknown/NA & $57(77)$ & $30(53)$ & $27(47)$ \\
\hline
\end{tabular}

$\mathrm{HCC}=$ hepatocellular carcinoma; mut $=$ mutant; $\mathrm{NA}=$ not available; $\mathrm{pts}=$ patients; wt $=$ wild-type .

tebral body height), and to prevent neurological worsening in 2 of 4 vertebroplasties, all the corpectomies, as well as in 9 of 10 laminectomies. Fifteen lesions (13\%) received prior external beam radiation therapy (EBRT). The median dose for these prior radiation courses was $30 \mathrm{~Gy}$ (IQR $30-38$ Gy) delivered in 10 fractions (IQR 10-15 fractions) at a median of 8 months (IQR 5-11 months) prior to SRS. None of the lesions in this study were previously treated with SRS. Chemotherapy had been used prior to SRS for the majority of spinal metastases $(n=95,83 \%)$.

The median total SRS dose prescribed was $20 \mathrm{~Gy}$ (IQR 20-24 Gy) in 1 fraction (IQR 1-3 fractions). The median SFED was 18 Gy (IQR 16-20 Gy) with a median GTV Dmin of 16 Gy (IQR 14-19 Gy). Additional treatment characteristics are listed on a per-lesion basis in Table 2 .
TABLE 2. Prior therapy and SRS characteristics per lesion $(n=$ 114)

\begin{tabular}{|c|c|c|c|}
\hline Parameter & $\begin{array}{l}\text { Whole } \\
\text { Cohort }\end{array}$ & $\begin{array}{c}\text { SFED }<20 \\
\mathrm{~Gy}_{10}\end{array}$ & $\begin{array}{c}\text { SFED } \geq 20 \\
\mathrm{~Gy}_{10}\end{array}$ \\
\hline No. of lesions & 114 & 65 & 49 \\
\hline \multicolumn{4}{|l|}{$\begin{array}{l}\text { No. of prior chemo regi- } \\
\text { mens, } n(\%)\end{array}$} \\
\hline 0 & $19(17)$ & $12(63)$ & $7(37)$ \\
\hline 1 & $37(33)$ & $23(62)$ & $14(38)$ \\
\hline 2 & $22(19)$ & $12(55)$ & $10(45)$ \\
\hline$\geq 3$ & $36(31)$ & $18(50)$ & $18(50)$ \\
\hline \multicolumn{4}{|l|}{ Prior surgery to lesion, $n(\%)$} \\
\hline No & $98(86)$ & $57(58)$ & $41(42)$ \\
\hline Vertebroplasty & $4(4)$ & $3(75)$ & $1(25)$ \\
\hline Corpectomy & $2(2)$ & $1(50)$ & $1(50)$ \\
\hline Laminectomy & $10(9)$ & $4(40)$ & $6(60)$ \\
\hline \multicolumn{4}{|l|}{$\begin{array}{l}\text { Prior radiation therapy to } \\
\text { lesion, } \mathrm{n}(\%)\end{array}$} \\
\hline No & $99(87)$ & $51(52)$ & $48(48)$ \\
\hline EBRT & $15(13)$ & $14(93)$ & $1(7)$ \\
\hline \multicolumn{4}{|l|}{ Lesion location, $\mathrm{n}(\%)$} \\
\hline Cervical & $12(11)$ & $6(50)$ & $6(50)$ \\
\hline Thoracic & $57(50)$ & $33(58)$ & $24(42)$ \\
\hline Lumbar & $40(35)$ & $23(58)$ & $17(42)$ \\
\hline Sacral & $5(4)$ & $3(60)$ & $2(40)$ \\
\hline Median GTV (IQR), $\mathrm{cm}^{3}$ & $19(7-42)$ & $19(8-47)$ & $18(6-34)$ \\
\hline Median PTV (IQR), $\mathrm{cm}^{3}$ & $32(12-50)$ & $27(10-62)$ & $33(13-49)$ \\
\hline Median SRS dose (IQR), Gy & $20(20-24)$ & $21(18-24)$ & $20(20-24)$ \\
\hline Median fraction (IQR) & $1(1-3)$ & $3(1-3)$ & $1(1-1)$ \\
\hline $\begin{array}{l}\text { Median prescription isodose } \\
\%(I Q R)\end{array}$ & $79(59-83)$ & $78(68-83)$ & $79(59-81)$ \\
\hline Median SFED 10 (IQR), Gy & $18(16-20)$ & - & - \\
\hline Median GTV Dmin (IQR), Gy & $16(14-19)$ & $16(14-19)$ & $17(13-19)$ \\
\hline Median SINS (IQR) & $6(4-8)$ & $6(5-7)$ & $7(4-8)$ \\
\hline Lytic, n (\%) & $33(29)$ & $25(76)$ & $8(24)$ \\
\hline Blastic, n (\%) & $37(32)$ & $21(57)$ & $16(43)$ \\
\hline Mixed, n (\%) & $44(39)$ & $19(43)$ & $25(57)$ \\
\hline \multicolumn{4}{|l|}{ SINS category, $\mathrm{n}(\%)$} \\
\hline Stable & $66(58)$ & $42(64)$ & $24(36)$ \\
\hline Potentially unstable & $47(41)$ & $23(49)$ & $24(51)$ \\
\hline Unstable & $1(1)$ & - & $1(100)$ \\
\hline
\end{tabular}

Chemo $=$ chemotherapy.

\section{Survival and Local Control}

The median follow-up after SRS was 11 months (IQR 3-18 months). The median survival following SRS was 15 months (IQR 5-27 months). The 1- and 2-year cumulative incidence rates of LF were $24 \%(95 \%$ confidence interval [CI] $16 \%-33 \%$ ) and $32 \%(95 \%$ CI $23 \%-42 \%)$, respectively (Fig. 1). Of the patients with the 33 lesions with LF, 17 (52\%) had Eastern Cooperative Oncology Group (ECOG) scores of $0-1,15(45 \%)$ had ECOG scores of 2-4, and 1 (3\%) had missing data. In contrast, of the patients with the 


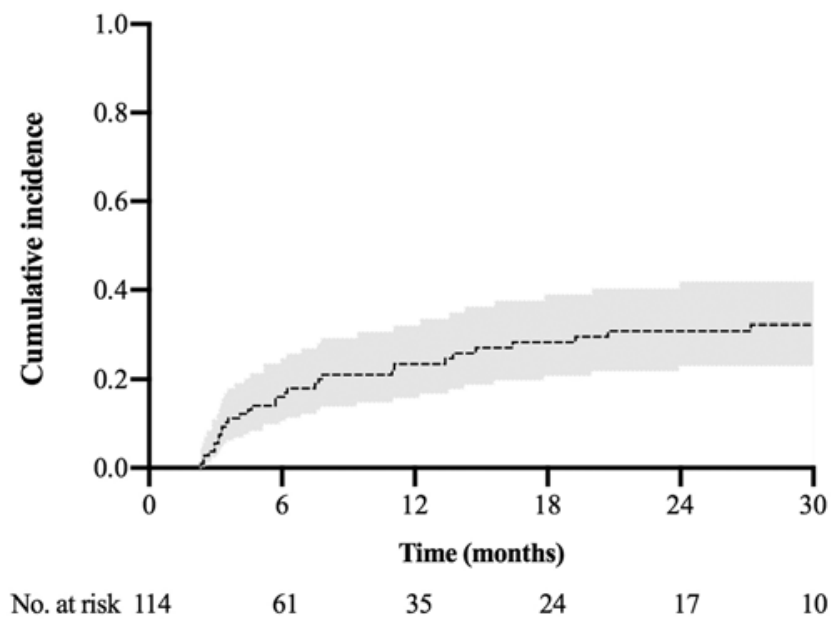

FIG. 1. Cumulative incidence of local failure after SRS to spinal metastases with 95\% Cls (gray shading).

81 lesions without LF, 59 (73\%) had ECOG scores of 0-1, and $22(27 \%)$ had ECOG scores of 2-4.

On univariable analysis, older age (hazard ratio [HR] 1.04 per year, 95\% CI 1.008-1.075, $\mathrm{p}=0.015)$ and SFED < $20 \mathrm{~Gy}_{10}$ (HR 3.23, 95\% CI 1.44-7.23, $\mathrm{p}=0.004$ ) were associated with a higher rate of LF. The 12-month cumulative incidence rates of LF for spinal metastases treated with $\mathrm{SFED} \geq 20 \mathrm{~Gy}_{10}\left(\mathrm{BED}>60 \mathrm{~Gy}_{10}\right)$ versus SFED $<20 \mathrm{~Gy}_{10}$ $\left(\mathrm{BED}<60 \mathrm{~Gy}_{10}\right.$ ) were $7 \%$ and $35 \%$, respectively (Fig. 2).

Primary histology was not associated with LF. Specifically, the 12-month cumulative incidence rates of LF for CRC and non-CRC GI spinal metastasis were 23\% (95\% CI $12 \%-36 \%$ ) and $24 \%$ (95\% CI 13\%-36\%), respectively $(\mathrm{p}=0.722)$. Spinal metastases from right-sided primary CRCs had significantly higher rates of LF compared to spinal metastases from left-sided primary CRCs (Fig. 3). The 12-month cumulative incidence rates of LF for spinal metastases from right- and left-sided primary CRCs were $39 \%(95 \% \mathrm{CI} 17 \%-60 \%)$ and $8 \%(95 \%$ CI $1.4 \%-24 \%)$, respectively $(\mathrm{p}=0.038)$.

The 12-month cumulative incidence rates of LF for non-CRC GI primary cancers were hepatocellular $40 \%$ (95\% CI 17\%-62\%), pancreatic 33\% (95\% CI 11\%-58\%), and other $9 \%$ (95\% CI $0.3 \%-37 \%)$. There were no failures in the neuroendocrine cohort in the 12 months following SRS; there was only 1 failure at 16 months following SRS.

$K R A S$ and $B R A F$ mutational status were also examined. $K R A S$ and $B R A F$ mutations were tested in 35 (47\% of the total patient cohort) and 17 (23\%) patients, respectively. Of those tested patients, KRAS mutations were identified in 7 patients (20\%) while BRAF mutation was identified in 1 patient (6\%). Among patients with CRC and mutational testing, neither $K R A S$ nor $B R A F$ mutations were associated with local control.

Prior radiation therapy or surgery to the target spinal metastasis, spinal location, GTV, GTV Dmin, receipt of prior chemotherapy, number of prior chemotherapy regimens, time since diagnosis, and SINS were also not significantly associated with LF. In multivariable analysis controlling for prior radiation therapy and GTV size,

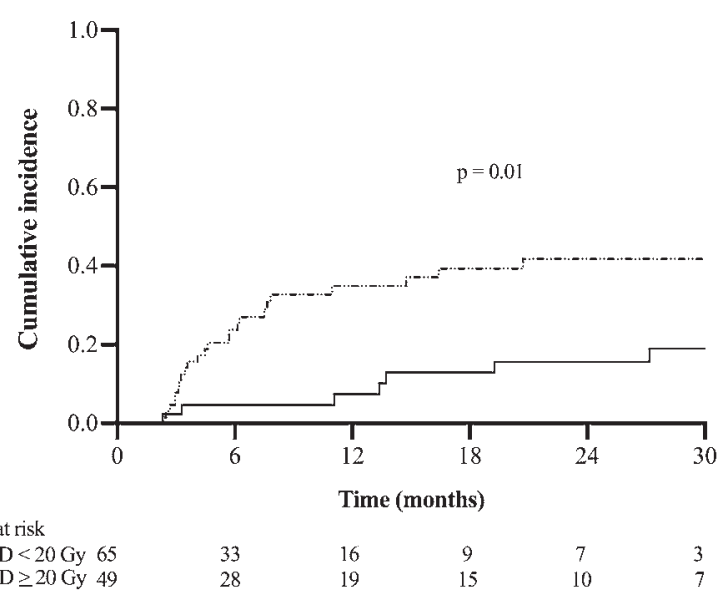

FIG. 2. Cumulative incidence of local failure by SFED. The solid line indicates lesions treated to SFED $\geq 20 \mathrm{~Gy}_{10}$, while the dashed line indicates lesions treated to SFED $<20 \mathrm{~Gy}_{10}$. Local failure was significantly higher in lesions treated to SFED $<20 \mathrm{~Gy}_{10}$.

SFED $<20 \mathrm{~Gy}_{10}\left(\mathrm{BED}<60 \mathrm{~Gy}_{10}\right)$ remained associated with increased LF rates (HR 2.92, 95\% CI 1.24-6.89, p $=0.014$ ).

\section{Toxicity}

Following SRS, $8 \%$ of patients experienced pain flare $(n=6)$ and were treated with pain medications and steroids. VCF occurred in 15 spinal metastases (13\%). The 1- and 2-year cumulative incidence rates of VCF were 7\% (95\% CI 3\%-12\%) and 8\% (95\% CI 4\%-14\%), respectively. Three patients were managed by surgery, 2 with vertebroplasty, and the remaining managed conservatively. For spinal metastases with VCF, the median SINS prior to SRS was 7 (IQR 6-9) and was not associated with SRS. Two lesions had prior EBRT treated with $30 \mathrm{~Gy}$ in 10 fractions and 37.5 Gy in 15 fractions. The median SRS dose was $20 \mathrm{~Gy}$ (IQR 18-22.5 Gy). We did not find a significant association of age, sex, primary histology, KRAS, BRAF, CRC sidedness, prior radiation therapy, spinal location, primary chemotherapy, number of prior chemotherapy regimens, time since diagnosis, GTV, GTV Dmin, or SINS with VCF. No patient developed cord, cauda equina, or spinal nerve toxicity following SRS.

\section{Discussion}

Similar to conventional radiotherapy, SBRT/SRS can provide local control and pain palliation of spinal metastases. However, metastases from GI primary cancers are believed to be more radioresistant. ${ }^{17}$ We found that the overall rate of LF for all patients was higher than expected compared to non-GI histologies. ${ }^{11,20,21}$ However, SRS at an SFED $\geq 20 \mathrm{~Gy}_{10}$ provided excellent local control compared to lower doses.

Poor outcomes with conventionally fractionated radiation for spine and bone metastases have been reported by multiple randomized trials. Several Radiation Therapy Oncology Group (RTOG) trials have evaluated lower radiation doses with more protracted courses of radiation compared to higher radiation doses with contracted 
courses of radiation. RTOG 7402 reported complete relief in only $57 \%$ of patients with a solitary osseous metastasis and did not find improved outcomes with higher doses (40.5 Gy in 3 weeks compared to 20 Gy in 1 week). ${ }^{41}$ Similarly, RTOG 9714 reported a complete response rate of only $15 \%$ and $18 \%$ at 3 months with 8 Gy in 1 fraction and 30 Gy in 10 fractions, respectively. ${ }^{19}$

SBRT/SRS has allowed the use of much higher doses of radiation for diverse tumor sites including brain, bone, lung, and liver. $1,23,25,27,29,32,39-41$ Compared to conventionally fractionated radiotherapy, the ablative doses used in SBRT/SRS can provide improved local control and palliation of symptoms. A recent phase II trial of 160 patients with nonspine bone lesions compared single-fraction SBRT using doses of 12-16 Gy in 1 fraction with conventionally fractionated radiotherapy (30 Gy in 10 fractions). SBRT was associated with higher pain response rates ( $77 \%$ vs $46 \%$ at 9 months) and better local control (100\% vs $76 \%$ at 2 years). ${ }^{12}$ For spinal metastases, SBRT/ SRS has been shown retrospectively and prospectively to achieve local control rates exceeding $90 \%$ with minimal toxicity in the de novo, re-irradiation, and postoperative settings, ${ }^{13-15,38,42,45}$ and even for histologies considered to be radioresistant. ${ }^{45}$ Yamada et al. reported their experience of 811 spinal metastases treated with a mean dose of 24 Gy and found histology-independent durable radiographic control in both radiosensitive and radioresistant tumor cohorts with a 4-year cumulative incidence of LF of $2.1 \%{ }^{46}$

Despite this, local control with SRS/SBRT of GI histologies, including hepatocellular carcinoma and CRC metastases, is not optimal. Table 3 includes select series of SRS/SBRT for metastases from GI primary cancers. Milano et al. found that colorectal, pancreatic, biliary, and liver metastases to the thorax, abdomen, pelvis, bone, or CNS had significantly worse local control compared to breast cancer metastases treated with SBRT/SRS. ${ }^{27}$ Another study reported a 1-year LF rate of $27 \%$ for spinal metastases from CRC treated with SRS (majority treated with doses of $27 \mathrm{~Gy}$ in 3 fractions or 18 Gy in 1 fraction). ${ }^{4}$ Similarly, Binkley et al. reported high rates of failure in CRC lung metastases treated with a median dose of $25 \mathrm{~Gy}$ (range 18-50 Gy) in 1 fraction, with 1- and 2-year rates of $26 \%$ and $42 \%$, respectively. ${ }^{5}$ A multiinstitutional cohort study reported 1- and 2-year LF rates of $33 \%$ and $45 \%$, respectively, with SBRT using a median dose of 42 Gy (range 22-60 Gy) in 6 fractions (range 1-6 fractions) for CRC liver metastases. ${ }^{8}$ Furthermore, this study suggested that a BED of 117 Gy would be needed for $90 \%$ local control of CRC liver metastases, which exceeds the doses typically used for spine SRS/SBRT.

Like prior studies, we found high rates of LF (1 year of $24 \%$ ) in our overall cohort of GI spinal metastases treated with SRS (median SFED 18 Gy). We found that doses equivalent to $20 \mathrm{~Gy}$ and higher in a single fraction were associated with improved LF rates (1 year of 7\%), suggesting that dose escalation may be a viable option to improve local control for GI histologies. Currently, spine SRS/ SBRT doses are variable, ranging anywhere from 16-24 Gy in 1 fraction to $30-40$ Gy in 5 fractions, ${ }^{37}$ and there are no firm guidelines for dosing schedule by histology.

Dose escalation needs to be explored in the context of

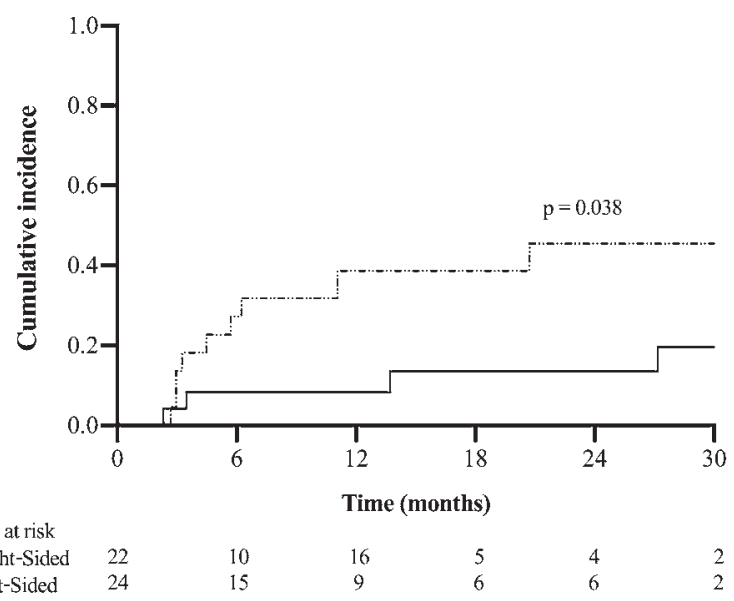

FIG. 3. Cumulative incidence of local failure for the CRC cohort by tumor sidedness. Local failure was significantly higher in those with right-sided CRC.

treatment-related toxicity, which can involve the esophagus, brachial and lumbosacral plexus, and most importantly, spinal cord. Radiation myelopathy is the most serious late effect of SRS and can result in paralysis and death. However, myelopathy is rare, with a less than $1 \%$ rate of myelopathy ${ }^{24,36}$ using a cord Dmax constraint of 14 Gy, ${ }^{17}$ as in RTOG 0631. Safe dose limits have also been proposed for the re-irradiation setting. ${ }^{28,30,31,35}$ Given the morbidity of local recurrence, spinal cord dose constraint relaxation is being explored in high-risk patients who may benefit from dose escalation..$^{15} \mathrm{VCF}$ is another risk that is unique with SBRT/SRS; risk of fracture with conventional radiation doses for bone metastases has been reported to be less than $5 \% .{ }^{9}$ We found that $13 \%$ of the treated lesions had VCF, consistent with prior pooled multiinstitutional data. Pooled data from the University of Toronto, MD Anderson Cancer Center, and Cleveland Clinic reported a $14 \%$ rate of VCF following spine SBRT, with factors significantly associated with VCF including higher dose per fraction, lytic tumor, baseline VCF, and spinal deformity. ${ }^{34}$ Cunha et al. was the first to report an association between dose and risk of VCF: those spinal lesions treated with doses 20 Gy or higher had an HR of 6.82 (95\% CI 1.83-25.42) for developing VCF. ${ }^{11}$ Establishing the dose with the right balance between these toxicities and local control will differ by histology, and fractionation ${ }^{42,43}$ and use of tumor-specific radiosensitizers ${ }^{6}$ may be ways to expand the therapeutic ratio.

Interestingly, we found that spinal metastases from a right-sided primary CRC had worse local control compared to metastases from left-sided CRC. Petrelli et al. found in a meta-analysis of 66 studies that left-sided primary tumor location was associated with a significantly reduced risk of death (HR 0.82, 95\% CI 0.79-0.84), independent of stage and use of adjuvant chemotherapy. ${ }^{33}$ These findings have also been reported among patients treated with radiation; Doi et al. reported outcomes for 39 CRC liver metastases treated with definitive radiotherapy and found that metastases from right-sided colon tumors had poorer local control. ${ }^{12}$ While it has been suggested 


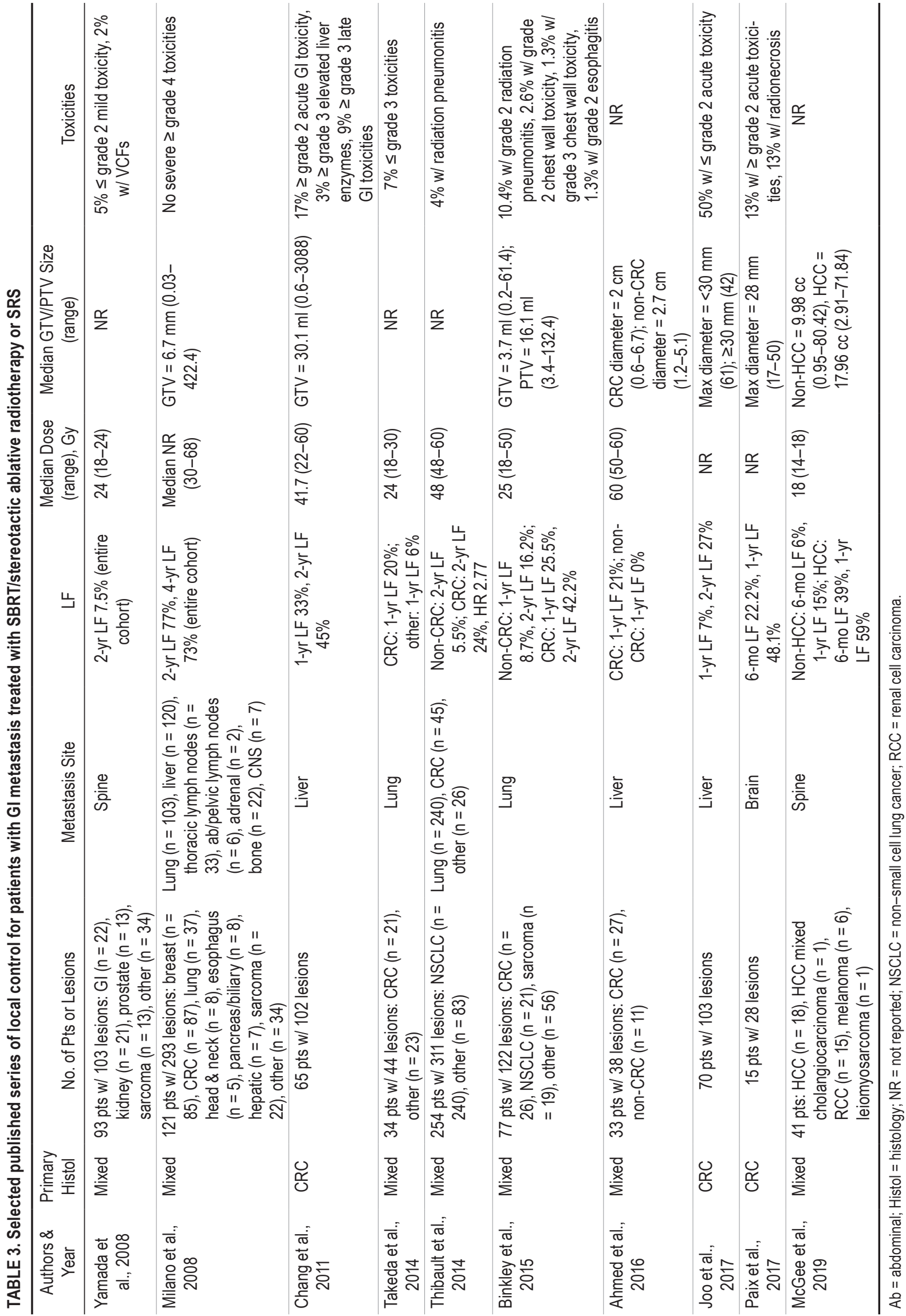


that surgical technique may contribute to worse outcomes for right-sided tumors,,$^{20}$ our findings suggest that primary tumor location may be a surrogate of more aggressive biology. Right- and left-sided colon tumors have differences in embryological origin (hindgut for left-sided and midgut for right-sided colon tumors) as well as in gut microbiota and mucosal immunology. ${ }^{16}$ Right-sided colon tumors may also follow different molecular pathogenic pathways, being more likely to have $\mathrm{CpG}$ island methylator phenotypes, $B R A F$ mutations, microsatellite instability, and defective mismatch repair genes..$^{21,22}$

Limitations of our study include its retrospective nature and small sample size. Patients included in this study were heterogeneous in terms of histology and systemic therapies received. However, we found that specific GI histology type and receipt of chemotherapy or number of lines of prior chemotherapy were not significantly associated with local control.

\section{Conclusions}

Spinal metastases from GI primary cancers have unacceptably high rates of LF compared to other histologies. However, this apparent radioresistance can be overcome by an SRS dose equivalent to $20 \mathrm{~Gy}_{10}$ or greater in a single fraction.

\section{References}

1. Ahmed KA, Caudell JJ, El-Haddad G, Berglund AE, Welsh EA, Yue B, et al: Radiosensitivity differences between liver metastases based on primary histology suggest implications for clinical outcomes after stereotactic body radiation therapy. Int J Radiat Oncol Biol Phys 95:1399-1404, 2016

2. Balagamwala EH, Naik M, Reddy CA, Angelov L, Suh JH, Djemil T, et al: Pain flare after stereotactic radiosurgery for spine metastases. J Radiosurg SBRT 5:99-105, 2018

3. Barzilai O, Fisher CG, Bilsky MH: State of the art treatment of spinal metastatic disease. Neurosurgery 82:757-769, 2018

4. Bernard V, Bishop AJ, Allen PK, Amini B, Wang XA, Li J, et al: Heterogeneity in treatment response of spine metastases to spine stereotactic radiosurgery within "radiosensitive" subtypes. Int J Radiat Oncol Biol Phys 99:1207-1215, 2017

5. Binkley MS, Trakul N, Jacobs LR, von Eyben R, Le QT, Maxim PG, et al: Colorectal histology is associated with an increased risk of local failure in lung metastases treated with stereotactic ablative radiation therapy. Int J Radiat Oncol Biol Phys 92:1044-1052, 2015

6. Brown JM, Diehn M, Loo BW Jr: Stereotactic ablative radiotherapy should be combined with a hypoxic cell radiosensitizer. Int J Radiat Oncol Biol Phys 78:323-327, 2010

7. Bufill JA: Colorectal cancer: evidence for distinct genetic categories based on proximal or distal tumor location. Ann Intern Med 113:779-788, 1990

8. Chang DT, Swaminath A, Kozak M, Weintraub J, Koong AC, Kim J, et al: Stereotactic body radiotherapy for colorectal liver metastases: a pooled analysis. Cancer 117:4060-4069, 2011

9. Chow E, Harris K, Fan G, Tsao M, Sze WM: Palliative radiotherapy trials for bone metastases: a systematic review. J Clin Oncol 25:1423-1436, 2007

10. Cox BW, Spratt DE, Lovelock M, Bilsky MH, Lis E, Ryu S, et al: International Spine Radiosurgery Consortium consensus guidelines for target volume definition in spinal stereotactic radiosurgery. Int J Radiat Oncol Biol Phys 83:e597e605, 2012
11. Cunha MVR, Al-Omair A, Atenafu EG, Masucci GL, Letourneau D, Korol R, et al: Vertebral compression fracture (VCF) after spine stereotactic body radiation therapy (SBRT): analysis of predictive factors. Int J Radiat Oncol Biol Phys 84:e343-e349, 2012

12. Doi H, Uemoto K, Suzuki O, Yamada K, Masai N, Tatsumi $\mathrm{D}$, et al: Effect of primary tumor location and tumor size on the response to radiotherapy for liver metastases from colorectal cancer. Oncol Lett 14:453-460, 2017

13. Garg AK, Shiu AS, Yang J, Wang XS, Allen P, Brown BW, et al: Phase $1 / 2$ trial of single-session stereotactic body radiotherapy for previously unirradiated spinal metastases. Cancer 118:5069-5077, 2012

14. Gerszten PC, Burton SA, Ozhasoglu C, Welch WC: Radiosurgery for spinal metastases: clinical experience in 500 cases from a single institution. Spine (Phila Pa 1976) 32:193-199, 2007

15. Ghia AJ, Guha-Thakurta N, Hess K, Yang JN, Settle SH, Sharpe HJ, et al: Phase 1 study of spinal cord constraint relaxation with single session spine stereotactic radiosurgery in the primary management of patients with inoperable, previously unirradiated metastatic epidural spinal cord compression. Int J Radiat Oncol Biol Phys 102:1481-1488, 2018

16. Gill SR, Pop M, Deboy RT, Eckburg PB, Turnbaugh PJ, Samuel BS, et al: Metagenomic analysis of the human distal gut microbiome. Science 312:1355-1359, 2006

17. Grimm J, LaCouture T, Croce R, Yeo I, Zhu Y, Xue J: Dose tolerance limits and dose volume histogram evaluation for stereotactic body radiotherapy. J Appl Clin Med Phys 12:3368, 2011

18. Guckenberger M, Mantel F, Gerszten PC, Flickinger JC, Sahgal A, Létourneau D, et al: Safety and efficacy of stereotactic body radiotherapy as primary treatment for vertebral metastases: a multi-institutional analysis. Radiat Oncol 9:226, 2014

19. Hartsell WF, Scott CB, Bruner DW, Scarantino CW, Ivker RA, Roach M III, et al: Randomized trial of short- versus long-course radiotherapy for palliation of painful bone metastases. J Natl Cancer Inst 97:798-804, 2005

20. Hohenberger W, Weber K, Matzel K, Papadopoulos T, Merkel S: Standardized surgery for colonic cancer: complete mesocolic excision and central ligation-technical notes and outcome. Colorectal Dis 11:354-365, 2009

21. Hutchins G, Southward K, Handley K, Magill L, Beaumont $\mathrm{C}$, Stahlschmidt J, et al: Value of mismatch repair, KRAS, and BRAF mutations in predicting recurrence and benefits from chemotherapy in colorectal cancer. J Clin Oncol 29:1261-1270, 2011

22. Iacopetta B: Are there two sides to colorectal cancer? Int J Cancer 101:403-408, 2002

23. Joo JH, Park JH, Kim JC, Yu CS, Lim SB, Park IJ, et al: Local control outcomes using stereotactic body radiation therapy for liver metastases from colorectal cancer. Int J Radiat Oncol Biol Phys 99:876-883, 2017

24. Katsoulakis E, Jackson A, Cox B, Lovelock M, Yamada Y: A detailed dosimetric analysis of spinal cord tolerance in high-dose spine radiosurgery. Int J Radiat Oncol Biol Phys 99:598-607, 2017

25. McGee HM, Carpenter TJ, Ozbek U, Kirkwood KA, Tseng TC, Blacksburg S, et al: Analysis of local control and pain control after spine stereotactic radiosurgery reveals inferior outcomes for hepatocellular carcinoma compared with other radioresistant histologies. Pract Radiat Oncol 9:89-97, 2019

26. Mik M, Berut M, Dziki L, Trzcinski R, Dziki A: Right- and left-sided colon cancer-clinical and pathological differences of the disease entity in one organ. Arch Med Sci 13:157-162, 2017

27. Milano MT, Katz AW, Schell MC, Philip A, Okunieff P: Descriptive analysis of oligometastatic lesions treated with 
curative-intent stereotactic body radiotherapy. Int J Radiat Oncol Biol Phys 72:1516-1522, 2008

28. Myrehaug S, Sahgal A, Hayashi M, Levivier M, Ma L, Martinez R, et al: Reirradiation spine stereotactic body radiation therapy for spinal metastases: systematic review. J Neurosurg Spine 27:428-435, 2017

29. Nguyen QN, Chun SG, Chow E, Komaki R, Liao Z, Zacharia R, et al: Single-fraction stereotactic vs conventional multifraction radiotherapy for pain relief in patients with predominantly nonspine bone metastases: a randomized phase 2 trial. JAMA Oncol 5:872-878, 2019

30. Nieder C, Gaspar LE, Ruysscher D, Guckenberger M, Mehta MP, Rusthoven CG, et al: Repeat reirradiation of the spinal cord: multi-national expert treatment recommendations. Strahlenther Onkol 194:365-374, 2018

31. Nieder C, Grosu AL, Andratschke NH, Molls M: Update of human spinal cord reirradiation tolerance based on additional data from 38 patients. Int J Radiat Oncol Biol Phys 66:1446-1449, 2006

32. Paix A, Antoni D, Adeduntan R, Noël G: Stereotactic radiation therapy of brain metastases from colorectal cancer: a single institution cohort. Cancer Radiother 21:199-204, 2017

33. Petrelli F, Coinu A, Lonati V, Barni S: A systematic review and meta-analysis of adjuvant chemotherapy after neoadjuvant treatment and surgery for rectal cancer. Int J Colorectal Dis 30:447-457, 2015

34. Sahgal A, Atenafu EG, Chao S, Al-Omair A, Boehling N, Balagamwala EH, et al: Vertebral compression fracture after spine stereotactic body radiotherapy: a multi-institutional analysis with a focus on radiation dose and the spinal instability neoplastic score. J Clin Oncol 31:3426-3431, 2013

35. Sahgal A, Ma L, Weinberg V, Gibbs IC, Chao S, Chang UK, et al: Reirradiation human spinal cord tolerance for stereotactic body radiotherapy. Int J Radiat Oncol Biol Phys 82:107-116, 2012

36. Sahgal A, Weinberg V, Ma L, Chang E, Chao S, Muacevic A, et al: Probabilities of radiation myelopathy specific to stereotactic body radiation therapy to guide safe practice. Int $\mathbf{J}$ Radiat Oncol Biol Phys 85:341-347, 2013

37. Sangha A, Korol R, Sahgal A: Stereotactic body radiotherapy for the treatment of spinal metastases: an overview of the University of Toronto, Sunnybrook Health Sciences Odette Cancer Centre, technique. J Med Imaging Radiat Sci 44:126-133, 2013

38. Sprave T, Verma V, Förster R, Schlampp I, Bruckner T, Bostel T, et al: Randomized phase II trial evaluating pain response in patients with spinal metastases following stereotactic body radiotherapy versus three-dimensional conformal radiotherapy. Radiother Oncol 128:274-282, 2018

39. Takeda A, Sanuki N, Kunieda E: Role of stereotactic body radiotherapy for oligometastasis from colorectal cancer. World J Gastroenterol 20:4220-4229, 2014

40. Thibault I, Poon I, Yeung L, Erler D, Kim A, Keller B, et al: Predictive factors for local control in primary and metastatic lung tumours after four to five fraction stereotactic ablative body radiotherapy: a single institution's comprehensive experience. Clin Oncol (R Coll Radiol) 26:713-719, 2014

41. Tong D, Gillick L, Hendrickson FR: The palliation of symptomatic osseous metastases: final results of the study by the Radiation Therapy Oncology Group. Cancer 50:893-899, 1982
42. Tseng CL, Soliman H, Myrehaug S, Lee YK, Ruschin M, Atenafu EG, et al: Imaging-based outcomes for 24 Gy in 2 daily fractions for patients with de novo spinal metastases treated with spine stereotactic body radiation therapy (SBRT). Int J Radiat Oncol Biol Phys 102:499-507, 2018

43. Wang XS, Rhines LD, Shiu AS, Yang JN, Selek U, Gning I, et al: Stereotactic body radiation therapy for management of spinal metastases in patients without spinal cord compression: a phase 1-2 trial. Lancet Oncol 13:395-402, 2012

44. Wong DAM, Fornasier VLM, MacNab I: Spinal metastases: the obvious, the occult, and the impostors. Spine (Phila Pa 1976) 15:1-4, 1990

45. Yamada Y, Bilsky MH, Lovelock DM, Venkatraman ES, Toner S, Johnson J, et al: High-dose, single-fraction imageguided intensity-modulated radiotherapy for metastatic spinal lesions. Int J Radiat Oncol Biol Phys 71:484-490, 2008

46. Yamada Y, Katsoulakis E, Laufer I, Lovelock M, Barzilai O, McLaughlin LA, et al: The impact of histology and delivered dose on local control of spinal metastases treated with stereotactic radiosurgery. Neurosurg Focus 42(1):E6, 2017

\section{Disclosures}

Dr. D. T. Chang reports direct stock ownership in ViewRay, Inc., and clinical or research support for this study from Varian Medical Systems, Inc. Dr. Gibbs reports receiving honoraria from Accuray, Inc. Dr. Li reports being a consultant for Medtronic, being on the speakers bureau for Synthes, and receiving clinical or research support for this study from Bristol-Myers Squibb.

\section{Author Contributions}

Conception and design: Pollom, Sandhu, Soltys. Acquisition of data: Sandhu, Benson, Kumar. Analysis and interpretation of data: Sandhu, Benson, Von Eyben. Drafting the article: Pollom, Sandhu. Critically revising the article: Pollom, Sandhu, Kumar, DT Chang, Gibbs, Hancock, Meola, SD Chang, Li, Hayden-Gephart, Soltys. Reviewed submitted version of manuscript: Pollom, Sandhu. Approved the final version of the manuscript on behalf of all authors: Pollom. Statistical analysis: Von Eyben. Administrative/ technical/material support: Sandhu. Study supervision: Pollom, Soltys.

\section{Supplemental Information Previous Presentations}

Portions of this work were presented at the 2019 American Society of Radiation Oncology (ASTRO) Meeting in Chicago, Illinois, on September 16, 2019.

\section{Correspondence}

Erqi L. Pollom: Stanford Cancer Institute, Stanford, CA. erqiliu@ stanford.edu. 